\title{
WOULD YOU RECOGNIZE UNIVERSAL DESIGN FOR LEARNING IF YOU SAW IT? TEN PROPOSITIONS FOR NEW DIRECTIONS FOR THE SECOND DECADE OF UDL
}

Dave L. Edyburn

\begin{abstract}
As I read the latest issue of the Learning Disability Quarterly, I was appreciative of the essay by King-Sears (2009) highlighting the value of universal design for learning (UDL) to the learning disability community. The allure of UDL has captured the imagination of many educators and policy makers. The recent reauthorization of the Higher Education Opportunity Act of 2008 (Public Law 110-315, Section 202, I, A), for example, requires colleges of education that receive federal funding for teacher quality partnership grants to report on the outcomes of UDL training within their preservice preparation programs. King-Sears' efforts to encourage the learning disability community to dialogue about UDL are noteworthy and timely.

Given that the King-Sears piece was featured as a "Commentary" article designed to spark conversation about contemporary topics, I would like to take this opportunity to extend the conversation and highlight nuances associated with translating UDL theory into practice. As someone who has been involved in helping individual teachers as well as schools, states, provinces, and policy makers translate UDL theory into practice, I am concerned about the ability of the profession to implement a construct that it cannot define.
\end{abstract}

DAVE L. EDYBURN, Ph.D., Department of Exceptional Education, University of Wisconsin-Milwaukee.

\section{HISTORICAL CONTEXT}

As King-Sears (2009) noted, the origin of the term universal design for learning is generally attributed to David Rose, Anne Meyer, and colleagues at the Center for Applied Special Technology (CAST). However, a fact that is often overlooked is that the principles of UDL were developed following the 1997 reauthorization of the Individuals with Disabilities Education Act (IDEA).

Some readers will recall that during the late 1990s there was considerable interest in the United States in the issue of inclusion. While students with disabilities had gained physical access to the general education classroom, concerns were being raised about how these students would gain access to the "general curriculum." The issues associated with access to the curriculum were at the forefront of CAST's work, and in 1999 federal grant monies were awarded to establish the National Center on Accessing the General Curriculum, which became instrumental in garnering national attention for the potential of UDL. 
As CAST's insights about UDL were taking shape, CAST staff presented their work at the annual Office of Special Education (OSEP) Project Directors' conference during the late 1990s. The work was extremely well received by the research community and led to the publication of an interpretive document (Orkwis \& McLane, 1998) that was disseminated extensively and served to generate the first wave of national attention to the construct. CAST used additional publication outlets to describe their ideas about how universal design could be applied within education (Meyer \& Rose, 2000; Rose \& Meyer, 2000).

The second wave of widespread attention to UDL came in 2002, when Rose and Meyer published a book that has become the definitive work on UDL (available from http://www.cast.org/teachingeverystudent/ideas/ tes/). They elaborated on the conceptual framework of UDL and how it is grounded in emerging insights about brain development, learning, and digital media. They also pointed to the disconnect between an increasingly diverse student population and a "one-size-fits-all" curriculum, arguing that this would not produce the academic achievement gains expected of 21st-century global citizens. Challenging educators to think of the curriculum as disabled, rather than students, their insights in translating principles of universal design, which originated in architecture, to education are commensurate with advances characterized as a major paradigm shift (Edyburn \& Gardner, 2009).

\section{POLICY FOUNDATIONS}

In the 2004 reauthorization of the Individuals with Disabilities Education Act (IDEA), the term universal design was officially defined within U.S. federal law (20 U.S.C. § 1401) governing special education: "The term universal design has the meaning given the term in section 3 of the Assistive Technology Act of 1998" (U.S.C. $\S 3002)$.

Following the backward chain of legal reference, the definition of universal design as it was included in the Assistive Technology Act of 1998 is as follows:

The term "universal design" means a concept or philosophy for designing and delivering products and services that are usable by people with the widest possible range of functional capabilities, which include products and services that are directly usable (without requiring assistive technologies) and products and services that are made usable with assistive technologies. (U.S.C. § 3002)

Next, consider how the terms are defined in the Higher Education Opportunity Act of 2008 (Public Law 110-315, Section 103, a):

(23) UNIVERSAL DESIGN. - The term 'universal design' as the meaning given the term in section 3 of the Assistive Technology Act of 1998. (29 U.S.C. 3002)

(24) UNIVERSAL DESIGN FOR LEARNING. - The term universal design for learning means a scientifically valid framework for guiding educational practice that -

(A) provides flexibility in the ways information is presented, in the ways students respond or demonstrate knowledge and skills, and in the ways students are engaged; and

(B) reduces barriers in instruction, provides appropriate accommodations, supports, and challenges, and maintains high achievement expectations for all students, including students with disabilities and students who are limited English proficient.

Notice how the definition of UD evolved from a concept or philosophy in 1998 to a scientifically validated framework in 2008. Of concern is the fact that to date, there has been little research on UDL although there is a significant body of work on universally designed assessment (e.g., Ketterlin-Geller, 2005; Russell, Hoffman, \& Higgins, 2009; Thompson, Johnstone, \& Thurlow, 2002). Without an adequate base of primary research, an analysis of research evidence that establishes UDL as a scientifically validated intervention is not possible (Edyburn, in press). Evidently, the work CAST compiled to support various components of UDL design principles (http://www.cast.org/publications/ UDLguidelines/index.html) was mischaracterized by lobbyists and written into federal law. The claim that UDL has been scientifically validated through research cannot be substantiated at this time.

\section{DEVELOPMENTAL PERSPECTIVES: THE FIRST 10 YEARS}

Within a period of 10 years, UDL has captured the imagination of policy makers, researchers, administrators, and teachers. The mantra that evolved from our understanding of the value of curb cuts and the like, "good design for people with disabilities benefits everyone," provides a powerful rationale for exploring the large-scale application of UDL in education - the lack of a credible research base notwithstanding.

The transition from inaccessible design to universally accessible design will involve awareness training, new technical development, and time. Consequently, the vision of universal accessibility will not be attained quickly. The A3 Model (Schwanke, Smith, \& Edyburn, 2001) illustrates the ebb and flow of concurrent interactions between advocacy, accommodation, and accessibility across a three-phase developmental cycle required to achieve universal accessibility (see Figure 1).

Advocacy efforts raise awareness of inequity and highlight the need for system change to respond to the 
needs of individuals with disabilities. Accommodations are the typical response to advocacy. Inaccessible environments and materials are modified and made available. Typically, accommodations are provided upon request. While this represents a significant improvement over situations found in the earlier phase, accommodations tend to maintain inequality since (a) there may be a delay (e.g., time needed to convert a handout from print to Braille); (b) it may require special effort to obtain (e.g., call ahead to schedule); or (c) it may require going to a special location (e.g., the only computer with text enlargement software is in the library). Accessibility describes an environment where access is equitably provided to everyone at the same time. Often this is accomplished through outstanding design (e.g., ergonomic furniture, software with accessibility and performance supports built in). All three factors are present in each phase. However, the differential impact of the three components in terms of time, effort, and focus is illustrated by the waves across phases.

The A3 Model illustrates the UDL change process experienced by individuals and organizations. CAST's work on UDL paints a vision of the world in which instructional environments, materials, and strategies are universally designed (as in the Accessibility Phase). They have created an outstanding series of products (i.e., WiggleWorks, 1994; Thinking Reader, 2004; UDL Editions by CAST, 2008; CAST UDL Book Builder, 2009a; CAST Science Writer, 2009b) that provide experiential evidence of what UDL principles could look like in practice.

In the first 10 years of UDL implementation, we have shared the message of UDL with substantial numbers of educators (Advocacy Phase). However, the reality is that once we understand the principles of UDL, we move from Advocacy to Accommodations. This means

Figure 1. The A3 Model illustrates the dynamic nature of advocacy, accommodations, and accessibility in three developmental phases. The differential impact of the three components in terms of time, effort, and focus is illustrated by the waves across phases.

\section{A3 Model and Transition of Approach}

\section{A System's Overall Approach at any point in time (expressed as the proportions of the three strategies used to meet the needs of people with disabilities)}

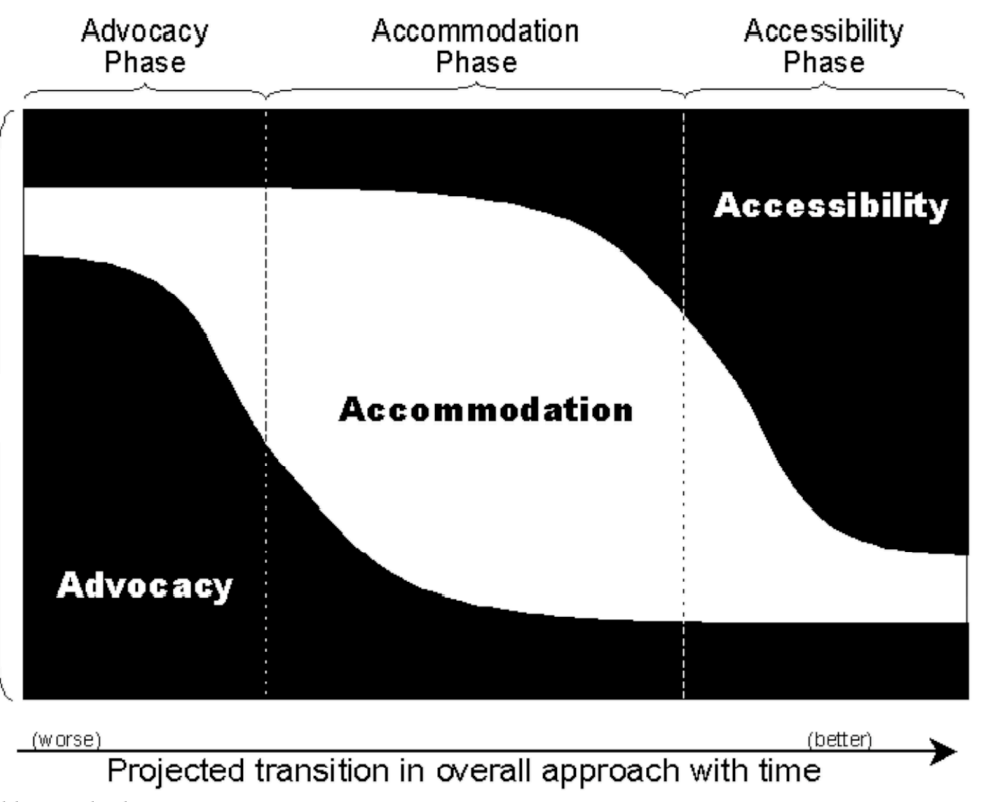

Copyright@ 2000, 2001 by Schwanke, Smith, and Edyburn. Used with permission. 
that while we are awaiting widespread availability of the promise of UDL (Accessibility Phase), we are left to our own devices to try to apply the UDL principles to create more accessible accommodations (e.g., "Since the web page does not feature audio, let me show you how to copy the text and paste it into a text to speech tool."). The A3 Model illustrates why many early disciples of UDL find themselves struggling to achieve the potential of UDL within the current limitations of instructional design and product development.

Just as cooperative learning is not defined as whenever two students talk with each other, and co-teaching is not defined as whenever two teachers share the same classroom, we must be able to operationalize the construct of UDL. As UDL is disseminated to broader audiences, I am concerned about the fundamental problem: Will we recognize UDL if we see it? Unfortunately, I have been in many situations where educators, administrators, researchers, or product developers were making claims that their instructional practices are based on UDL principles, but I simply was not able to see the connection.

\section{TEN PROPOSITIONS FOR NEW DIRECTIONS FOR THE SECOND DECADE OF UDL}

As UDL enters its second decade, the profession must begin to address some developmental milestones. As every parent knows, the transition from child to adolescent can be turbulent and challenging at times. Similarly, as UDL enters its second decade, I believe it is important to foreshadow some nuances about UDL that have caused minor outbursts in recent years and are likely to explode into typical teenage angst in the years ahead.

In the following analysis, I advance 10 propositions that the profession should consider in order to clearly discern what UDL is and how we might go about implementing the construct with fidelity to properly measure the effects of UDL.

\section{Proposition \#1: Universal Design in Education Is Fundamentally Different from Universal Design in the Built Environment.}

Observation. As King-Sears (2009) noted, the field of UDL has its genesis in the original construct of universal design as it was developed in architecture. However, in my opinion the seven principles of universal design (Center for Universal Design, 1997) offer little insight into how to design instruction to ensure that diverse learners are successful. For example, the interactions between individuals and the built environment (e.g., stairs, doorways, countertops) are static and limited. In contrast, the interaction between a reader and a text involves complex physical, cognitive, and social interactions to make sense of the information.

New directions. In order to achieve the promise of UDL, I believe the profession must recognize that the essence of UDL lies in the field of instructional design rather than architecture. UDL helps us understand the value of technology for providing access and engagement in learning - prerequisites for learning outcomes. However, much more attention must be devoted to the complex interactions between learning objectives, learner characteristics, performance support strategies, technology, and outcome. Reference to the seven principles of universal design serves only as a distraction.

\section{Proposition \#2: UDL Is Fundamentally About Proactively Valuing Diversity.}

Observation. King-Sears (2009) observed that there is considerable confusion about the roles of technology and UDL. I agree. I have often observed situations where teachers, administrators, and publishers claim they are implementing UDL simply because they are using multimedia or Web 2.0 tools. I disagree. I believe that there must be a priori evidence that the instructional designer understands academic diversity and is proactively building supports that will ensure that individual differences do not mitigate access and engagement. Otherwise, the result is simply a happy coincidence between the use of technology and new tools that students enjoy. UDL is more than simply integrating the latest technology tools into the curriculum.

New directions. I fear that the promise of UDL will not be achieved unless we begin to focus on developing diversity blueprints. I am inspired by the work of several authors (Burke, Hagan, \& Grossen, 1998; Coyne, Kameenui, \& Simmons, 2004; McLeskey \& Waldon, 2007; Tomlinson, 2004) who seek to understand the impact of various instructional designs on the success of diverse learners. Likewise, I am cognizant of research by Molenbroek and de Bruin (2006) that reveals that designers' assumptions about diversity directly impact the accessibility and usability of their product design. That is, when designers assume that everyone is like them (e.g., tall, short, average weight, able to read at grade level), the product they create will meet the needs of a narrow range of users.

Consider the recent fiasco with the Amazon Kindle, where designers failed to recognize that blind readers would want to use a hand-held reading device and that they would need voiced navigational menus - a design decision that was reversed in December 2009 after six months of complaints and disability advocacy (Amazon.com., 2009).

Without a diversity blueprint, it is unlikely that UDL designers will be able to design products that meet the 
Figure 2. A representation of the achievement gap illustrates typical development by the diagonal line where students gain one unit of achievement for each year they are in school. Underachievement results in students falling further and further behind and represents a performance gap that is exceedingly difficult to close. Over 50 years of educational research documents the presence of achievement gaps for several groups of students: students with disabilities, students of color, students of poverty, and English language learners.

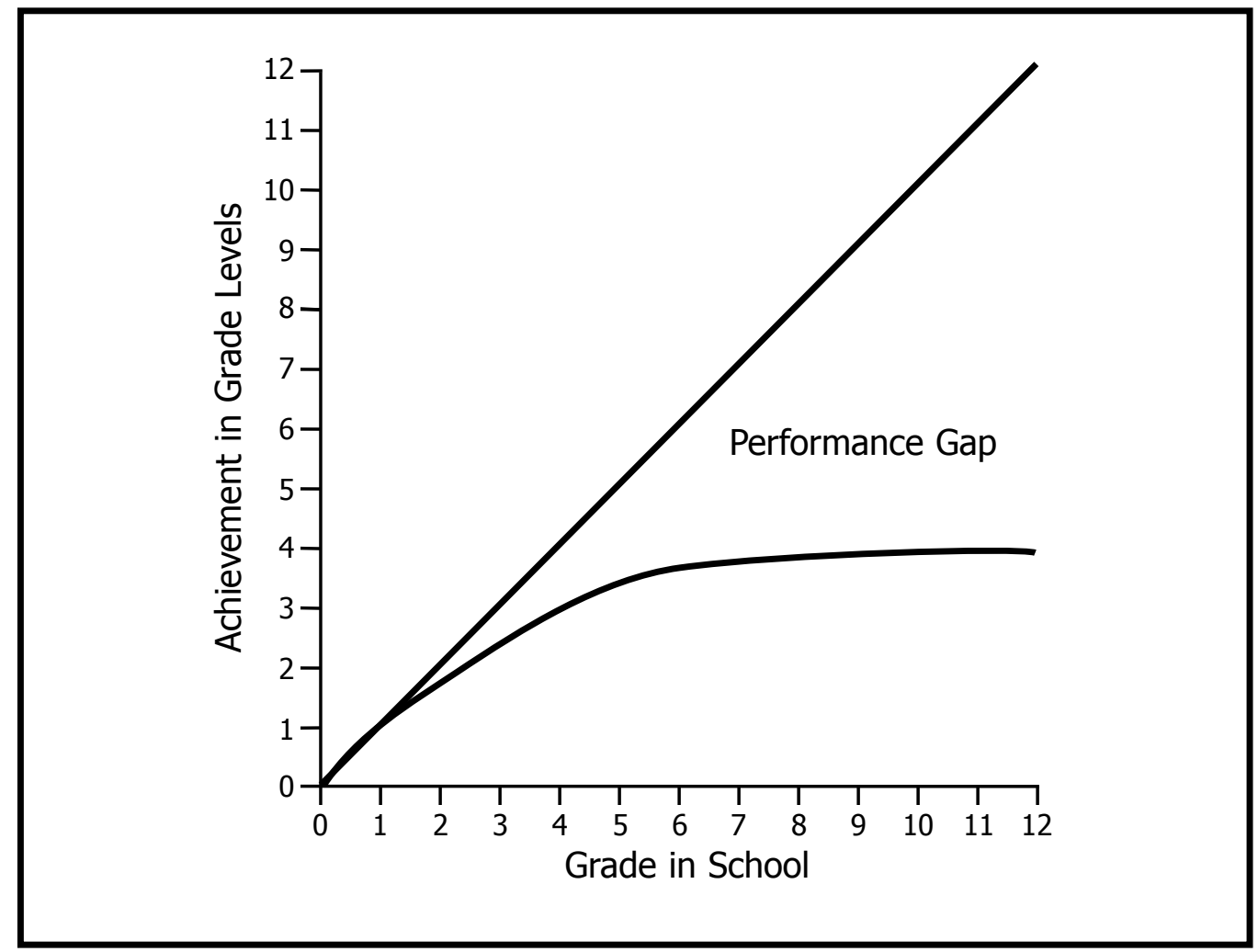

accessibility and usability needs of all individuals, because they do not understand the special needs of some individuals. Clearly, there is much more to learn about how to meet the instructional needs of diverse individuals. However, until we begin describing the salient nature of those differences in ways that inform design, it is unlikely that we will design products that meet the needs of all learners.

\section{Proposition \#3: UDL Is Ultimately About Design.}

Observation. UDL is about design. Design is fundamentally about problem solving. Instructional design is about the efficacy of learning. Central to all of these constructs is evidence of intentionality and how problems can be resolved through innovative design. Technology is simply the delivery system.

New directions. A fundamental question that has yet to be addressed is whether or not the demands of daily instruction will allow teachers to function effectively as instructional designers. That is, are teachers the principal stakeholders as they design and deliver instruction in accordance with UDL principles? Or, is UDL a task for developers who make instructional products?

Given the difficulties I have observed in trying to scale UDL implementation beyond single classrooms, I believe it may be necessary to rethink UDL as a product 
development intervention. Perhaps the teacher's role is more appropriately associated with implementing principles of differentiated instruction (which may include some products that have been universally designed).

\section{Proposition \#4: Universal Design for Learning Is Not Just Good Teaching.}

Observation. Another means of understanding UDL is to clarify what it is not. Unfortunately, statements like the following are found in the literature: "universal design for learning is just good teaching" or "it is like what you have always done" (Castellani, Mason, \& Orkwis, 2005; Orkwis \& McLane, 1998).

I believe these statements reflect a fundamental misunderstanding of the functions of design, proactively valuing diversity, and intentionality. What we have always done is known as the achievement gap (see Figure 2). Educational research illustrates that marginalized students such as students with disabilities, culturally and linguistically diverse students, students from low socio-economic backgrounds, and English language learners experience chronic school failure; hence the focus on calculating adequate yearly progress (AYP) within the No Child Left Behind legislation. This pattern of performance is not evidence that existing instructional practices are effective for all students.

New directions. UDL represents a 21st-century intervention that seeks to use emerging insights gained from research in diverse fields such as brain imaging, learning sciences, instructional design, and technology. Good teaching has never been able to address the full range of diversity found in a classroom.

To allow this type of language to continue in UDL discussions renders the construct meaningless. More important, statements such as "UDL is just good teaching" serve to preserve the status quo, which marginalizes low-performing students. We must find ways to define and measure implementation of UDL in order to discern when it is being implemented and when it is not.

\section{Proposition \#5: Universal Design for Learning Does Not Occur Naturally.}

Observation. On more than one occasion, I have heard the statement, "Many teachers are already doing UDL; they just don't know that's what it is called." This is a corollary to the previous proposition. Since UDL is the convergence of multiple disciplines, I reject the notion that there is a natural trait within effective teachers that allows them to implement UDL without knowing that they are doing so. I do not believe that UDL occurs naturally. In some respects, this issue may simply be a permutation of the timeless argument about whether teaching is an art or a science (Dewey, 1929; Gage, 1978; Skinner, 1954).
New directions. Much like any other integrative cognitive skill, UDL must be recognized as a learned skill, one that is refined over time, to produce high levels of performance. One way of advancing this issue would be to host a national design competition where contestants were challenged to solve an instructional problem by creating an innovative universally designed instructional product. It may also be appropriately to design studies to empirically test this proposition. We must refocus our efforts to train the key stakeholders in UDL principles that make meaningful differences in student engagement and learning.

\section{Proposition \#6: Technology Is Essential for Implementing UDL.}

Observation. King-Sears (2009) addresses the issue of whether or not UDL can be implemented without technology. Others have suggested that UDL is just like assistive technology, such that it can be implemented as no-tech, low-tech, or high-tech. I reject these notions. The reason why UDL is possible today as opposed to the 1950 s or 1970 s is that digital technology provides a high degree of flexibility. Paper-based instructional technologies (e.g., worksheets, textbooks) commit information to fixed formats and cannot match the array and flexibility of supports provided in a digital environment (e.g., alter the font size, color contrast, text to speech, hyperlinks for explanatory aids, agents that offer strategy suggestions, movies that supplement text). An example of this point is the subject of a recent YouTube video where a high schooler struggles to navigate his traditional textbook since it fails to provide the digital supports he is grown accustom to (Joe's NonNetbook; http://www.youtube.com/watch?v=skhpm EZWuRQ).

New directions. Why is computer technology essential for a majority of 21st-century activities outside of school but optional for helping students achieve high standards within school? When will a computer be considered essential for all students so that they can access and engage in a curriculum that is appropriate for their learning needs? To suggest that the potential of UDL can be achieved without technology is simply another way to maintain the status quo. Fortunately, the current price trends for Netbooks (they are becoming more and more affordable) may render this discussion moot within a few years.

\section{Proposition \#7: UDL Is Not Assistive Technology.}

Observation. The relationship between UDL and assistive technology has been a point of confusion for many educators (Rose, Hasselbring, Stahl, \& Zabala, 2005). If, for example, a building has an electronic door sensor to open the front door automatically, is it reasonable to conclude that wheelchairs will no longer be 
needed? Assistive technology devices and services are delivered reactively after a referral and evaluation of an individual student. UDL is given to everyone with the understanding that those who need specialized support will use the tools when they need them (i.e., embedded, just-in-time supports).

This is a critical paradigm shift that fully acknowledges the impact of peer pressure at the middle and secondary level. To meet the needs of some, UDL is committed to giving the tools to everyone. Assistive technology may be pre-empted by UDL interventions; however, as the example above illustrates, assistive technology and UDL may also co-exist.

New directions. Academic performance problems are not limited to students with disabilities. Therefore, why should technologies that enhance academic performance be restricted to students with disabilities? When new information is introduced in schools, learners perform as novices; that is, their performance is significantly different than that of experts. However, with proper instruction, the performance of a novice can be enhanced to very high levels. Additional research and development is needed in the area of cognitive prostheses (Edyburn, 2006) in order to clarify the benefit of tools and strategies that serve as scaffolds (temporarily needed and discarded) vs. tools that augment performance (always needed for acceptable performance).

Twenty-first-century instruction will likely need to alter instructional practices in order to place students in the role of Goldilocks - they try multiple options to determine which option is "just right" for ensuring their performance is acceptable to meet high standards. Principles of fairness indicate that equity is achieved when every student receives what he or she needs (Welch, 2000).

\section{Proposition \#8: It Is Necessary to Measure the Prim- ary and Secondary Impact of UDL.}

Observation. As King-Sears (2009) pointed out, one of the promises of UDL is that by focusing on the special needs of students with disabilities we can design solutions that positively impact other students. This principle can be illustrated by the example of the zero-entry swimming pool. The original design problem focused on how to enable people in wheelchairs to enter a pool. Clearly, the needs of the primary audience have been effectively met through this design. If the design innovation only helps a disability group, the intervention is simply an assistive technology. When the secondary impact of the zero-entry pool is examined, we observe that the majority of the users of the shallow end of the pool are parents with young children, teenagers, and senior citizens. This phenomenon illustrates an innovative tactic for quantifying and evaluating UDL claims by measuring and analyzing primary and secondary impact.

In contrast, when word prediction software is given to everyone, it is not a tool that continues to be used by everyone because it often interferes with the keyboarding performance of accomplished writers and typists. Consequently, it must be considered assistive technology, rather than UDL.

New directions. Instructional designers need to explicitly describe the intended user of a product. When the product is implemented within schools, appropriate research methodologies must measure the impact of the intervention on the primary audience as well as the rest of the students in an inclusive classroom. Data analysis should focus on discerning whether or not the product successfully produced the desired gains in the targeted audience. Secondary analysis should examine whether there were additional effects within the inclusive classroom such as are observed with the zero-entry swimming pool or whether the effects were more like word prediction software that offered benefits only to a small group. Further development of research analyses of the primary and secondary effect of UDL is essential for fostering a new generation of data-based discussions about UDL efficacy.

\section{Proposition \#9: Claims of UDL Must Be Evaluated on the Basis of Enhanced Student Performance.}

Observation. One of the significant flaws in a federal law (Higher Education Opportunity Act of 2008) that states that UDL is a scientifically validated framework is that CAST's UDL framework does not feature a component associated with the measurement of student learning outcomes. All three of the "multiple means" statements by CAST focus on providing multiple concurrent interventions. As a result, within existing conceptualizations of UDL, there is no clear way to measure claims that UDL is effective for enhancing the academic performance of diverse students. This is a significant shortcoming for anyone trying to operationalize, implement, and evaluate a UDL program.

New directions. If UDL is nothing more than providing students with alternatives, it fails significantly as a new paradigm for enhancing educational achievement, as it is simply another futile attempt to argue that schools needs more resources. I choose to believe the critical focus of UDL is its emphasis on the variables that can be manipulated to produce high performance. I am inspired by Tomlinson's (1999) conceptual work on the design of equalizers that could be utilized to manipulate key instructional variables to make curriculum accessible and engaging.

Research has demonstrated a relationship between deep learning and high levels of performance and 
expertise (Csikszentmihalyi, 1990; Schlechty, 2002). UDL outcome measurement needs to focus on the benefits that result from access and sustained engagement: Expertise and expert performance. That is, sustained engagement in learning tasks, of increasing difficulty and complexity, leads to high levels of learning and performance. The notion of applying a computer interface to a digital body of knowledge and then allowing the student to manipulate the information in ways that make it accessible (i.e., physical, sensory, and cognitive), at a level of appropriate challenge, has everything to do with the process of developing expertise. Ultimately, we need to understand how to measure the contributions of UDL to sustained engagement and development of expertise.

\section{Proposition \#10: UDL Is Much More Complex Than We Originally Thought.}

Observation. Understanding the potential of UDL is seductively easy. Its exponential growth indicates that it is the right idea at the right time. However, it has proven far easier to help the various stakeholders understand the potential of UDL than it has been to implement UDL on a large scale. And now that more people are "doing UDL," it is not clear what the outcomes are.

New directions. As we head into the second decade of "doing UDL," it is time for a new generation of thinking about UDL. Defining UDL as a subfield within instructional design will provide a knowledge base that is more relevant than looking to architecture for insight. Likewise, we must become serious about defining the key variables that impact instructional achievement and develop algorithms and tools that modularize the design process so we can develop more UDL materials more quickly and more cost effectively. We need to clarify the core stakeholders (developers or teachers) who will be trained to create UDL products. We need to understand what it means to implement UDL. We need to understand how to measure the outcomes of UDL. And, finally, we need to renew our commitment to equitably serving all students in the event that our UDL efforts fall short.

\section{CONCLUDING THOUGHTS}

As UDL is aligned with response-to-intervention initiatives, it is important for the learning disability community to engage in dialogue about the principles and practices of UDL. Without a doubt, UDL holds considerable promise. In this article I have offered an analysis of the developmental progress of UDL and described 10 propositions that need to be addressed as we go forward. Unless serious intellectual energy is devoted to addressing the current shortcomings of the UDL construct, within the next 10 years we may be commemorating the passing of another education fad.

\section{REFERENCES}

Amazon.com. (2009, December 7). Blind and vision-impaired readers to benefit from new Kindle features in 2010 (press release). Retrieved December 12, 2009, from http://phx.corporate-ir. net/phoenix.zhtml?c=176060\&p=irol-newsArticle\&ID=1362556 highlight $=$

Burke, M. D., Hagan, S. L., \& Grossen, B. (1998). What curricular designs and strategies accommodate diverse learners? Teaching Exceptional Children, 31(1), 34-38.

Castellani, J., Mason, C., \& Orkwis, R. (2005). Universal design for learning: A guide for teachers and education professionals. Arlington, VA: Council for Exceptional Children.

Center for Applied Special Technology. (1994). WiggleWorks (software). New York: Scholastic.

Center for Applied Special Technology. (2004). Thinking Reader (software). Watertown, MA: Tom Snyder Productions.

Center for Applied Special Technology. (2008). UDL Editions by CAST. Available at http://udleditions.cast.org/

Center for Applied Special Technology. (2009a). CAST UDL Book Builder. Available at http://bookbuilder.cast.org/

Center for Applied Special Technology. (2009b). CAST Science Writer. Available at http://sciencewriter.cast.org/

Center for Universal Design. (1997). The principles of universal design. Retrieved December 11, 2009, from http://www.design. ncsu.edu/cud/about_ud/udprinciplestext.htm/

Coyne, M. D., Kameenui, E. J., \& Simmons, D. C. (2004). Improving beginning reading instruction and intervention for students with LD: Reconciling "all" with "each." Journal of Learning Disabilities, 37(3), 231-239.

Csikszentmihalyi, M. (1990). Flow: The psychology of optimal experience. New York: Harper \& Row.

Dewey, J. (1929). The sources of a science of education. New York: Liveright.

Edyburn, D. L. (2006). Cognitive prostheses for students with mild disabilities: Is this what assistive technology looks like? Journal of Special Education Technology, 21(4), 62-65.

Edyburn, D. L. (in press). Understanding the quality of the science supporting the special education technology evidence base. Journal of Special Education Technology, 25(1).

Edyburn, D., \& Gardner, J. E. (2009). Readings in special education technology: Universal design for learning. Arlington, VA: Council for Exceptional Children.

Gage, N. L. (1978). The scientific basis of the art of teaching. New York: John Wiley.

The Higher Education Opportunity Act (Public Law 110-315). Retrieved December 9, 2009, from http://www.ed.gov/policy/ highered/leg/hea08/index.html/

Individuals With Disabilities Education Act. (1997). Pub. L. No. 105-17.

Ketterlin-Geller, L. R. (2005). Knowing what all students know: Procedures for developing universal design for assessment. Journal of Technology, Learning, and Assessment, 4(3). Electronic Journal. Retrieved on December 21, 2005, from http://www. bc.edu/research/intasc/jtla/journal/v4n2.shtml/

King-Sears, M. (2009). Universal design for learning: Technology and pedagogy. Learning Disability Quarterly, 32, 199-201.

McLeskey, J., \& Waldon, N. (2007) Making differences ordinary in inclusive classrooms. Intervention in School and Clinic, 42(3), 162168.

Meyer, A., \& Rose, D.H. (2000). Universal design for individual differences. Educational Leadership, 58(3), 39-43.

Molenbroek, J. F., \& de Bruin, R. (2006). Anthropometry of a friendly rest room. Assistive Technology, 18(2), 196-204.

The No Child Left Behind Act of 2001 (2001). Pub. L. No. 107-110. 
Orkwis, R., \& McLane, K. (1998). A curriculum every student can use: Design principles for student access. OSEP Topical Brief. Reston, VA: Council for Exceptional Children.

Rose, D. H., Hasselbring, T. S., Stahl, S., \& Zabala, J. (2005). Assistive technology and universal design for learning: Two sides of the same coin. In D. Edyburn, K. Higgins, \& R. Boone (Eds.), Handbook of special education technology research and practice (pp. 507-518). Whitefish Bay, WI: Knowledge by Design.

Rose, D. H., \& Meyer, A. (2000). The future is in the margins: The role of technology and disability in educational reform. A report prepared for the U.S. Department of Education Office of Special Education Technology. Washington, DC: USDOE.

Rose, D., \& Meyer, A. (2002). Teaching every student in the digital age. Alexandria, VA: ASCD.

Russell, M., Hoffman, T., \& Higgins, J. (2009). NimbleTools: A universally designed test delivery system. Teaching Exceptional Children, 42(2), 6-12.

Schlechty, P. (2002). Working on the work: An action plan for teachers, principals, and superintendents. San Francisco: Jossey-Bass.

Schwanke, T. D., Smith, R. O., \& Edyburn, D. L. (2001). A3 model diagram developed as accessibility and universal design instructional tool. RESNA 2001 Annual Conference Proceedings, 21, RESNA Press.
Skinner, B. F. (1954). The science of learning and the art of teaching. Harvard Educational Review, 24(2), 86-97.

The Technology-Related Assistance Act for Individuals With Disabilities. (1988). Pub. L. No. 100-407.

Thompson, S. J., Johnstone, C. J., \& Thurlow, M. L. (2002). Universal design applied to large-scale assessments (NCEO Synthesis Report 44). Minneapolis: University of Minnesota, National Center on Educational Outcomes.

Tomlinson, C. A. (1999). The differentiated classroom: Responding to the needs of all learners. Alexandria, VA: ASCD.

Tomlinson, C. A. (2004). The Mobius effect: Addressing learner variance in schools. Journal of Learning Disabilities, 37(6), 516524.

Welch, A. B. (2000). Responding to student concerns about fairness. Teaching Exceptional Children, 33(2), 36-40.

Please address correspondence about this article to: Dave Edyburn, Department of Exceptional Education, University of WisconsinMilwaukee, 3409 North Downer Avenue, Milwaukee, WI 53211; e-mail: edyburn@csd.uwm.edu 